\title{
Letter to the Editor regarding Mocanu et al. Ongoing Inconsistencies in Weight Loss Reporting Following Bariatric Surgery: a Systematic Review. Obesity Surgery https://doi.org/10.1007/s11695-018-03702-6Mocanu
}

\author{
Nick Finer ${ }^{1}$ (D) \\ Published online: 16 March 2019 \\ (C) Springer Science+Business Media, LLC, part of Springer Nature 2019
}

Mocanu and colleagues importantly draw attention to the continued varied reporting of weight-related outcomes after bariatric surgery and the barrier this presents to comparative analyses. They equate reporting body mass index (BMI) with weight, while of course BMI is a derived mathematical term (weight in $\mathrm{kg} /$ height in $\mathrm{m})^{2}$, a proxy for obesity. BMI changes should therefore reflect both a re-measured weight and remeasured height. Not unique to reports on surgical interventions, height is rarely re-measured at the time of postintervention assessment: the preoperative height is assumed to be constant. In these circumstances, any BMI change is merely a weight change modified by the constant value of height ${ }^{2}$. Statistical significance testing of BMI changes will give the spuriously identical $p$ value and confidence intervals to comparisons of weight changes. While the assumption of height constancy may be valid for comparisons made over a short time period, they are probably not over longer periods of time since height decreases with age at a rate of $-0.102 \mathrm{~cm} /$ year for men and $-0.165 \mathrm{~cm} /$ year for women aged $50-59$ so leading to artefactual increases in BMI [1]. As the authors of Baltimore Longitudinal Study of Aging concluded "True height loss with aging must be taken into account when height

Nick Finer

n.finer@ucl.ac.uk

1 National Centre for Cardiovascular Prevention and Outcomes, UCL Institute of Cardiovascular Science, Nomura House, 1 St Martin's le Grand, London EC1A 4NP, UK (or indexes based on height) is used in physiologic or clinical studies." Additionally, the development of osteoporosis [2] following bariatric surgery could lead to accelerated vertebral height loss and greater inaccuracies. This is not an issue addressed in the American Society for Metabolic and Bariatric Surgery recommendations [3]. Authors reporting BMI changes should be explicit as to whether these are based on an assumption of height constancy or on a re-measured height.

\section{Compliance with Ethical Standards}

Conflict of Interest The authors declare that they have no conflict of interest.

\section{References}

1. Sorkin JD, Muller DC, Andres R. Longitudinal change in height of men and women: implications for interpretation of the body mass index: the Baltimore longitudinal study of aging. Am J Epidemiol. 1999;150:969-77.

2. Center JR, White CP. Bariatric surgery, weight loss and bone. Nat Rev Endocrinol. 2013;9:630-2.

3. Hopkins JC, Howes N, Chalmers K, et al. Outcome reporting in bariatric surgery: an in-depth analysis to inform the development of a core outcome set, the BARIACT study. Obes Rev. 2015;16:88106.

Publisher's Note Springer Nature remains neutral with regard to jurisdictional claims in published maps and institutional affiliations. 